\title{
SCREENING OF MAIZE (ZEA MAYS L.) INBRED LINES UNDER WATER DEFICIT CONDITIONS
}

\author{
*MASOOD M ${ }^{1}$, AHSAN $M^{1}$, SADAQAT HA ${ }^{1}$, AWAN $F^{2}$ \\ ${ }^{I}$ Department of Plant Breeding and Genetics, University of Agriculture, Faisalabad, Pakistan \\ ${ }^{2}$ Centre of Agriculture Biochemistry and Biotechnology, University of Agriculture, Faisalabad, Pakistan \\ *Corresponding author e-mail: mmasoodmessage@gmail.com
}

(Received, $14^{\text {th }}$ February 2020, Accepted $3^{\text {rd }}$ May 2020)

\begin{abstract}
Development of the selection criteria and selection of crop plant genotypes is a crucial and important task of plant breeders. The present study was designed to screen out the drought or water deficit tolerant maize genotypes. Fifty genotypes were taken from maize germplasm restored by the Department of Plant Breeding and Genetics University of Agriculture, Faisalabad, Pakistan. One set of genotypes were grown under 100\% field capacity while other set at 50\% field capacity in wire house conditions. The significant contrasts were observed in genotypes of various attributes under ordinary and stress timeframe. The traits root length and root shoot ratio by mass showed the high heritability and genetic advance and genotypic correlation with each other under water deficit condition provided the basis for the selection. The principle component analysis showed that the genotypes A545, AES204, WM13RA were chosen on the premise of better performance for most of the traits under study. These lines may be used in further breeding program as candidate parents for the development of drought tolerant hybrids.
\end{abstract}

Keywords: maize, genetic variability, genetic advance, genotypic correlation, heritability, principle component analysis, water deficit

\section{Introduction}

The rise in atmospheric $\mathrm{CO}_{2}$ could lead to global warming and changes in precipitation patterns. Increasing temperature and altered soil moisture due to climate change are expected to decrease food crop yield over the next 50 years. The productivity and plant growth of many crops plants are mainly affected by the drought in most of the tropical and sub tropic regions of the world. Maize is an important $\mathrm{C}_{4}$ cereal crop plant grown in many countries of the world. It has been grown on an area of 183 million hectare and production of about 1021 Mt throughout the world (FAO, 2013). In Pakistan, maize is ranked third after wheat and rice among the cereals (Anonymous, 2013). Due to its multipurpose utilization, its demand will become double around 2050. The maize grain yield has been influenced by many environmental factors, among all of them the drought has been considered to be the most significant (Yin et al. 2016). In fact, both drought occurrence and severity are projected to be increased by 2050 (Zhao and Luo 2007). Drought is known to affect morphology, photosynthesis, dry matter (DM) and grain yield (Hao et al. 2016, Gheysari et al. 2017). It has been widely recognized that maize during the growing season is prone to drought (Çakir
2004, Saseendran et al. 2014). It has been reported that the drought stress induced stomata closure and caused damaging in photosynthetic system (Lawlor and Uprety 1993, Flexas et al. 2012). Sunlight deficit (solar radiation) usually resulted in photoinhibition (light-induced decrease in photochemical activity) (Terashima et al. 1994, Sharwood et al. 2014). Genetic variability is basic tool for the plant breeder to develop the tolerant genotypes which can cope with agro-climatic changing in near future. The well structured knowledge of plant genetics o for the climate change is necessary to understand the ground realities of the conditions (Thirunani et al., 2000). The present study was designed to develop selection criteria of such traits with high genotypic correlation, genetic advance, and heritability to produce maize genotypes, effective in water usage even under water deficit conditions.

\section{Material method}

Site description

The experiment was conducted during the maizegrowing season of 2015 at wire house of the Department of Plant Breeding and Genetics, University of Agriculture Faisalabad, Pakistan $\left(31.4504^{\circ} \mathrm{N}, 73.1350^{\circ} \mathrm{E}\right)$. The climate of the region is continental monsoon with four distinct seasons. It is at its peak in July and August during monsoon 
season. The annual high temperature was recorded as $31.3^{\circ} \mathrm{C}$ while $743 \mathrm{~mm}$ the mean annual precipitation. About $60 \%$ of precipitation received between July and August. The soil is the typical soil consists of young stratified silt loam or very fine sand loam which makes the subsoil weak in structure.

\section{Collection of the germplasm}

Fifty exotic and elite inbred lines were collected from the germplasm of the Department of Plant Breeding and Genetics. Two sets of genotypes were grown in the wire house according the factorial randomized complete block design. One set of inbred lines were seeded under normal condition (100\% field capacity). The second set was sown in wire house under water deficit condition ( $50 \%$ FC) in the polythene bag. All other agronomic suggested procedures were implemented. The data was recorded after 21 days of the sowing. The following plant characters were studied; root length (RL: cm), shoot length (SL: cm), fresh root weight (FRW: g) fresh shoot weight (FSW: g), dry root weight (DRW: g), dry shoot weight (DSW: g) and root shoot length ratio (RSL ratio)

Table 1. Maize inbred lines for the experiment

\begin{tabular}{llcl}
\hline $\begin{array}{l}\text { Inbred } \\
\text { lines }\end{array}$ & Name & $\begin{array}{l}\text { Inbred } \\
\text { lines }\end{array}$ & Name \\
\hline 1 & M-14 & 26 & PB77 \\
2 & A50-2 & 27 & 52B-4 \\
3 & A495 & 28 & 53P4 \\
4 & A509 & 29 & 83 P1 \\
5 & A545 & 30 & 20P2-1 \\
6 & A556 & 31 & L7-2 \\
7 & AES204 & 32 & 70 NO-2 \\
8 & Antigua-1 & 33 & 150P1 \\
9 & OH-28 & 34 & HY7 \\
10 & OH 33-1 & 35 & IC654 \\
11 & OH410 & 36 & JY12 \\
12 & W64SD & 37 & ML1 \\
13 & W64TMS & 38 & ML3 \\
14 & WMBRA & 39 & ML4 \\
15 & WF-9 & 40 & ML6 \\
16 & W187R & 41 & ML8 \\
17 & W10 & 42 & ML9 \\
18 & WA3748 & 43 & ML11 \\
19 & W82-3 & 44 & ML12 \\
20 & B-34 & 45 & ML14 \\
21 & B-34-2B & 46 & ML15 \\
22 & B-42 & 47 & ML17 \\
23 & Q-66 & 48 & ML18 \\
24 & Q-97 & 49 & ML20 \\
25 & N48-94 & 50 & ML21 \\
\hline Statistical and B10metrical & &
\end{tabular}

\section{Statistical and Biometrical analysis}

The means were separated by the least significant difference (LSD) test at the probability level of $0.05 \%$. The Estimate of broad sense heritability was recorded as the method outlined by Reeve and Robertson (1953) respectively. Genetic advance was calculated according to the method suggested by Johnson et al. (1955)._Low water stress effects of several traits were observed in the graph under both normal and water deficit conditions using XLSTAT. Principle component analysis was performed according to Gabriel, (1981) for both of the treatments separately using most variable principle factor in the form of biplot that was 2D scatter diagram showed the scattering pattern of genotypes and traits.

\section{Results}

\section{Summary Statistics}

The mean comparisons, minimum values, maximum values and standard deviation for normal and stress conditions were presented in the statistics summary (Table 2). Under normal condition the RL was ranged from $5 \mathrm{~cm}$ to $13.5 \mathrm{~cm}$ with mean $10.1 \pm 1.425 \mathrm{~cm}$ whereas under water deficit condition it was ranged from $7 \mathrm{~cm}$ to $16.5 \mathrm{~cm}$ with mean $10.85 \pm 2.16 \mathrm{~cm}$. The SL was ranged from $10.75 \mathrm{~cm}$ to $21 \mathrm{~cm}$ with mean $14.22 \pm 2.21 \mathrm{~cm}$ under well water or normal condition while under low moisture stress condition it was ranged from $9.75 \mathrm{~cm}$ to $18.25 \mathrm{~cm}$ with mean value $13.86 \pm 1.46 \mathrm{~cm}$. Under normal condition the RW was ranged from the $2.49 \mathrm{~g}$ to $11.98 \mathrm{~g}$ with mean $5.05 \pm 1.70 \mathrm{~g}$ whereas under stress condition it was ranged from $2.64 \mathrm{~g}$ to $6.4 \mathrm{~g}$ with mean $4.06 \pm 0.742 \mathrm{~g}$. The SW was ranged from $0.885 \mathrm{~g}$ to $4.26 \mathrm{~g}$ with mean $1.93 \pm 0.61 \mathrm{~g}$ under well water condition while under low moisture stress it was ranged from $0.675 \mathrm{~g}$ to $2.59 \mathrm{~g}$ with mean value $1.49 \pm 0.379 \mathrm{~g}$. Under normal condition the DRW ranged from the $0.403 \mathrm{~g}$ to $2.335 \mathrm{~g}$ with mean $1.04 \pm 0.40 \mathrm{~g}$ whereas under stress condition it was ranged from $0.385 \mathrm{~g}$ to $1.86 \mathrm{~g}$ with mean $0.9 \mathrm{~g} \pm 0.35 \mathrm{~g}$. The DSW was found from $0.168 \mathrm{~g}$ to $0.67 \mathrm{~g}$ with mean $0.327 \pm 0.109 \mathrm{~g}$ under well water while under low moisture stress it was ranged from $0.178 \mathrm{~g}$ to $0.683 \mathrm{~g}$ with mean value $0.298 \mathrm{~g} \pm 0.094 \mathrm{~g}$. Under normal condition the RS ratio was ranged from the 1.366 to 10.59 with mean $3.018 \pm 1.528$ whereas under stress condition it was ranged from 1.188 to 6.493 with mean $3.763 \pm 1.265$.

\section{Genetic components in seedling traits}

Heritability helps to estimate the reliability of the phe notypic value in genetic research of the quantitative a ttributes of the plant (Ahmed et al., 2011; Falconer and Mackay, 1996). Under normal condition, heritability was found moderate and low for most of the attributes under consideration. The heritability was found for different traits under normal condition; RL (51.182\%), SL (63.425\%), RW (69.65\%), SW (67.35\%), DRW (49.789\%), DSW (47.941\%), RS ratio $(57.701 \%)$. The genetic advance was found for RL (17.1\%), SL (22.54\%), RW (52.51\%), SW (48.472\%), DRW (46.02\%), DSW (38.236\%), RS ratio $(67.78 \%)$, whereas under low moisture stress, 
heritability was found for RL $(89.696 \%)$, SL (51.172\%), RW (43.371\%), SW (34.142\%) DRW $(34.142 \%)$, DSW $(46.372 \%)$, RS length ratio (73.311\%) while genetic advance was found for RL (37.810\%), SL (12.83\%) RW (19.268\%), SW (21.718\%), DRW (43.84\%), DSW (51.184\%), RS ratio $(58.43 \%)$

Association under normal conditions

It was found that the RL showed significant genotypic correlation with SL (0.133), DSW (0.259), RS ratio (0.217), SL had significant genotypic correlation with RW (0.46), SW ( 0.80) DRW (0.39) ,DSW (0.75) and RS ratio (0.36), RW exhibited significant genotypic association with SW (0.57), DRW (0.30) and DSW (0.588), SW showed the positive and significant genotypic association with DSW (0.77) and RS ratio (0.499) under ordinary situation. While in water stress, RL showed the significant genotypic association with SL (0.28), RW (0.29), DRW (0.44) RS ratio (0.11), SL had

\section{Genotypic correlation}

genotypic correlation with RW (0.30), SW (0.74), DSW (0.50) RS ratio (0.19), SW with RS length ratio (0.42).

Table 2. Summary statistics for various maize traits under normal and stress conditions

\begin{tabular}{llrrrc}
\hline Variable & & \multicolumn{1}{c}{ Min } & \multicolumn{1}{c}{ Max } & Mean & \multicolumn{1}{c}{ S.D } \\
\hline RL & Normal & 5.000 & 13.500 & 10.106 & 1.425 \\
& Stress & $\mathbf{7 . 0 0 0}$ & $\mathbf{1 6 . 5 0 0}$ & $\mathbf{1 0 . 8 5 0}$ & $\mathbf{2 . 1 6 2}$ \\
SL & Normal & 10.750 & 21.000 & 14.223 & 2.218 \\
& Stress & $\mathbf{9 . 7 5 0}$ & $\mathbf{1 8 . 2 5 0}$ & $\mathbf{1 3 . 8 6 9}$ & $\mathbf{1 . 4 6 8}$ \\
RW & Normal & 2.495 & 11.980 & 5.050 & 1.702 \\
& Stress & $\mathbf{2 . 6 4 5}$ & $\mathbf{6 . 4 6 0}$ & $\mathbf{4 . 0 6 2}$ & $\mathbf{0 . 7 4 2}$ \\
SW & Normal & 0.885 & 4.265 & 1.936 & 0.619 \\
& Stress & $\mathbf{0 . 6 7 5}$ & $\mathbf{2 . 5 9 5}$ & $\mathbf{1 . 4 9 7}$ & $\mathbf{0 . 3 7 9}$ \\
DRW & Normal & 0.403 & 2.335 & 1.049 & 0.407 \\
& Stress & $\mathbf{0 . 3 8 5}$ & $\mathbf{1 . 8 6 3}$ & $\mathbf{0 . 9 0 0}$ & $\mathbf{0 . 3 5 3}$ \\
DSW & Normal & 0.168 & 0.673 & 0.327 & 0.109 \\
& Stress & $\mathbf{0 . 1 7 8}$ & $\mathbf{0 . 6 8 3}$ & $\mathbf{0 . 2 9 8}$ & $\mathbf{0 . 0 9 4}$ \\
RS & Normal & 1.366 & 10.591 & 3.018 & 1.528 \\
& Stress & $\mathbf{1 . 1 8 8}$ & $\mathbf{6 . 4 9 3}$ & $\mathbf{3 . 7 6 3}$ & $\mathbf{1 . 2 6 5}$ \\
\hline
\end{tabular}

Table 3. Genotypic correlation of various traits of maize under normal and water stress condition

\begin{tabular}{llllllll}
\hline Traits & & SL & RW & SW & DRW & DSW & RS \\
\hline RL & Normal & $0.1338^{*}$ & 0.06 & 0.1472 & $0.2597^{*}$ & 0.0760 & $0.2171^{*}$ \\
& Stress & $\mathbf{0 . 2 8 9 7 *}$ & $\mathbf{0 . 2 9 9 1 *}$ & $\mathbf{0 . 1 4 7 4}$ & $\mathbf{0 . 4 4 9 7 *}$ & $\mathbf{0 . 2 0 3 2}$ & $\mathbf{0 . 1 0 8 8}$ \\
SL & Normal & & $0.4699^{*}$ & $0.8071^{*}$ & $0.3946^{*}$ & $0.7547^{*}$ & $0.3665^{*}$ \\
& Stress & & $\mathbf{0 . 3 0 6 6 ^ { * }}$ & $\mathbf{0 . 7 4 9 3} *$ & $\mathbf{0 . 0 3 7 3}$ & $\mathbf{0 . 5 0 2 7} *$ & $\mathbf{0 . 1 9 6 8}$ \\
RW & Normal & & & $0.5764^{*}$ & $0.3028^{*}$ & $0.5888^{*}$ & 0.1035 \\
& Stress & & & $\mathbf{0 . 3 3 4 8}$ & $\mathbf{0 . 3 3 5 7}$ & $\mathbf{0 . 3 0 8}$ & $\mathbf{0 . 1 2 7 7}$ \\
SW & Normal & & & & 0.171 & $0.7748^{*}$ & $0.4990^{*}$ \\
& Stress & & & & $\mathbf{0 . 2 4 3 8}$ & $\mathbf{0 . 2 8 4 6}$ & $\mathbf{0 . 4 2 1 1} *$ \\
DRW & Normal & & & & & 0.4653 & 0.2364 \\
& Stress & & & & & $\mathbf{0 . 1 2 7 7}$ & $\mathbf{0 . 4 5 6 8}$ \\
DSW & Normal & & & & & & 0.3926 \\
& Stress & & & & & $\mathbf{0 . 2 0 9 2}$ \\
\hline
\end{tabular}

Table 4. Genetic components of various traits of maize under normal and water stress condition

\begin{tabular}{cllllllll}
\hline SOV & & RL & SL & RW & SW & DRW & DSW & RS \\
\hline \multirow{2}{*}{ MS } & Normal & 4.063 & 9.843 & 5.795 & 0.766 & 0.332 & 0.024 & 4.67 \\
& Stress & $\mathbf{9 . 3 5 2}$ & $\mathbf{4 . 3 0 7}$ & $\mathbf{1 . 1}$ & $\mathbf{0 . 2 8 7}$ & $\mathbf{0 . 2 5}$ & $\mathbf{0 . 0 1 8}$ & $\mathbf{3 . 1 9 8}$ \\
\multirow{2}{*}{$\mathbf{h}^{2}$} & Normal & 51.182 & 63.425 & 69.65 & 67.35 & 49.789 & 47.941 & 57.701 \\
& Stress & $\mathbf{8 9 . 6 9 6}$ & $\mathbf{5 1 . 1 7 2}$ & $\mathbf{4 3 . 3 7 1}$ & $\mathbf{3 4 . 1 4 2}$ & $\mathbf{3 4 . 1 4 2}$ & $\mathbf{4 6 . 3 7 2}$ & $\mathbf{7 3 . 3 1 1}$ \\
& Normal & 17.1 & 22.54 & 52.51 & 48.472 & 46.02 & 38.236 & 67.78 \\
& Stress & $\mathbf{3 7 . 8 1}$ & $\mathbf{1 2 . 8 3}$ & $\mathbf{1 9 . 2 6 8}$ & $\mathbf{2 1 . 7 1 8}$ & $\mathbf{4 3 . 8 4}$ & $\mathbf{5 1 . 1 8 4}$ & $\mathbf{5 8 . 4 3}$ \\
\hline
\end{tabular}

Association under moisture stress situation

Principle component analysis

Biplot were formed by PCA for the normal and moisture stress condition separately to assess the genetic variability in the germplasm of maize. The genotypes near the origin of the biplot showed average performance for the characters. Genotypes for away from the origin in the direction of the vector arrow were indicators of the high mean and genotype with opposite the vector showed the poor performance for subjected traits. The biplot showed that RL, SL, RW, SW, DRW, DSW were found positive discriminator under normal conditions. The graph also depicted that $66.09 \%$ genetic variability in the mean data, PC1 and PC2 contribute $45.42 \%$ and $20.67 \%$ respectively. RL showed the acute angle $(<90)$ with most of the traits, had association with other seedling traits. The genotypes AES204, WM13RA were found high performance for most of the traits and ML 17 fall most distantly in the region of the RS ratio while W10,ML11, ML12, ICS65 showed poor performance under study under well water condition (Fig 1). The biplot showed that RL, SL, RW, SW, DRW, DSW were found positive 
discriminator under low moisture conditions. The graph also depicted $59.29 \%$ genetic variability in the mean data, PC1 and PC2 contribute $33.31 \%$ and $25.99 \%$ respectively. RL showed the acute angle $(<90)$ with most of the traits, had association with other seedling traits. The genotypes A545, AES204, WM13RA were found high performance for most of the traits while Q-66, ML 1, ML4 showed poor performance under study low water stress condition (Fig 2).

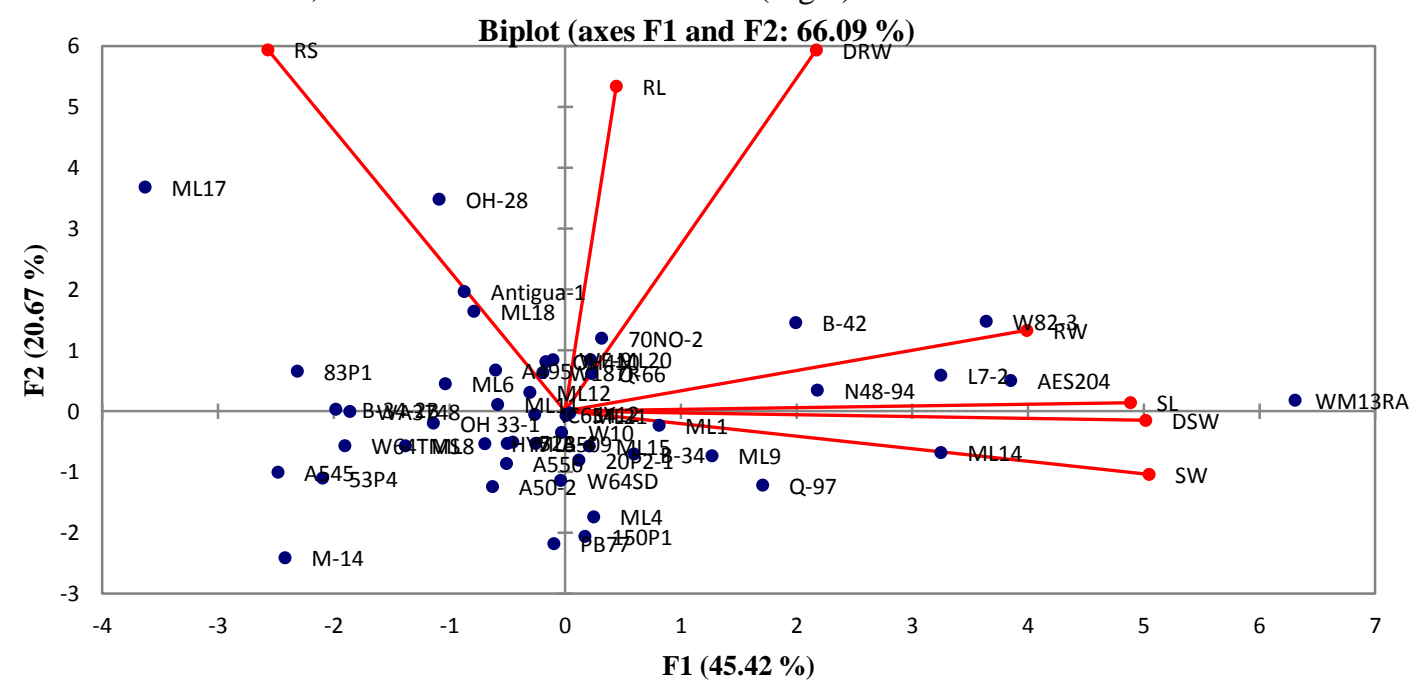

Fig. 1. Biplot of maize genotype under normal conditions Biplot (axes F1 and F2: 59.29 \%)

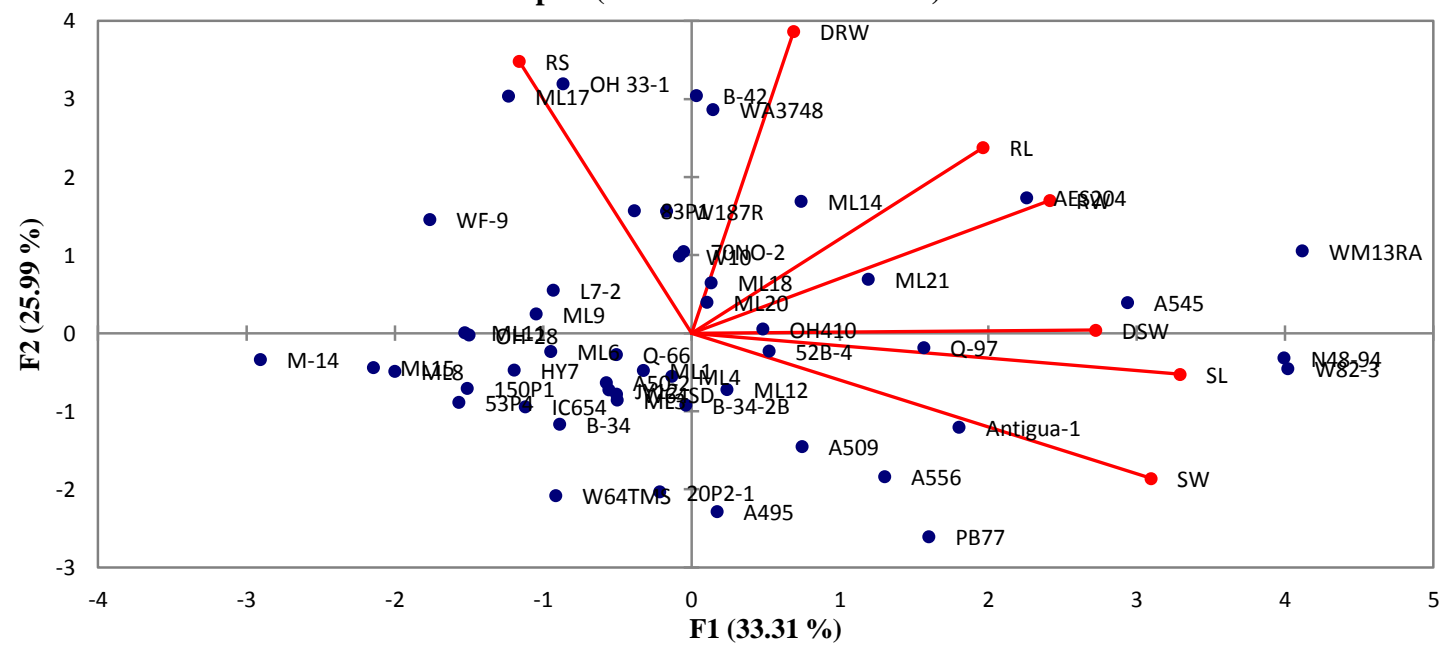

Fig. 2. Biplot of maize genotype under water deficit condition

\section{Discussion}

Many abiotic stresses, including low moisture enviro nment, severely affect maize production (Aslam et al, 2014). Maize plants are susceptible to low water tension during their life cycle with multiple morphophysiological and biochemical adversely specific growth and development levels (Anjum et al., 2017).

\section{Genetic variability}

A fundamental requirement for genetic advancement is the existence of genetic variability in any available germplasm at the alllic level. The comprehensive knowledge on the nature and magnitude of genetic variability is available to direct breeders to map out genetic improvement for breeding programs. Summary statistics indicated that the root length parameter showed the high value of mean in water stress condition than the normal condition showed the change of the trend from the shoot to root the same result was also reported by the Chohan, (2012); Ali et al., (2014) and Ahsan et al., (2008). The mean values of the SL, RW, SW, DRW, DSW, RS ratio decrease as compared to the normal conditions indicated the effect of drought on the plant growth (Farooq et al., 2009). The huge differences between maximum and minimum values and mean square showed the significant difference among the genotypes for most of the traits under study (Chohan, 2012, Ali et al., 2014; Ahsan, et al., 2008)

[Citation: Masood, M., Ahsan, M., Sadaqat, H.A., Awan, F. (2020). Screening of maize (Zea mays L.) lines under water deficit conditions. Biol. Clin. Sci. Res. J., 2020: 7. doi: https://doi.org/10.54112/bcsrj.v2020i1.7] 


\section{Development of selection criteria}

High heritability and genetic advance may help a plant breeder to predict the rate of the gain through the selection (Wang et al., 2011). The genetic reliability of the phenotypic values can be predicted from the heritability estimates, which may be used in the direction of the breeding improvement of the crops (Falconer and Mackay, 1996). The high heritability and genetic advance showed that trait can be fixed by simple selection (Najeeb et al., 2009). Under moisture stress situation shoot length, root weight, shoot weight showed the high heritability and genetic advances. The traits like shoot length and root shoot length ratio with high heritability and genetic advance provide the basis of selection of tolerant lines for low moisture stress. Correlation assisted selection can be used to bring fast improvements in the maize germplasm (Ogunniyan and Olakojo, 2014). Root length showed the positive correlation with dry root weight indicated that the accumulation of the dry matter due to uptake of the root under the water stress condition and genotypic correlation of root length with the root shoot length ratio may be served as selection criteria to select tolerant line.

\section{Selection of Genotype}

Principle component analysis is one of the multivariate analyses used to assess the variability and performance of different crops under normal and water deficit conditions with help of PC biplots (Ashraf et al., 2015; Latif et al., 2015; Mustafa et al., 2015). Based on the results of PCA biplot best performing genotypes were selected from exotic and elite germplasm of maize under water deficit condition. The genotypes such as A545, AES204 and WM13RA were found high performance for most of the traits were found drought tolerant and while lines Q-66, ML 1 andML4 was found drought susceptible.

\section{Conclusion}

It was concluded that the variability was found among the genotypes for all the traits under study. The traits such as the root length and root shoot length ratio had high heritability and genetic advance may be served as selection criteria. The genotype such as A545, AES204 and WM13RA may be selected as tolerant genotypes, these lines may be used in the further breeding programs as a parents to develop water deficit tolerant genotypes and hybrids.

\section{Conflict of interest}

The authors declared absence of any conflict of interest.

\section{References}

Ahsan, M., Zulqrnain, M.H. Saleem, M. and Aslam, M. (2008). Contribution of various leaf morpho-physiological parameters towards grain yield in maize. International Journal of Agriculture and Biology, 10(5):546-550,
Ali, Q., Ali, A., Waseem, M., Muzaffar, A., Ahmed, S., Ali, S., Bajwa, K.S., Awan, M.F., Samiullah, T.R., Nasir I.A., and Husnain, T. (2014). Correlation analysis for morphophysiological traits of maize (Zea mays L.). Life Science Journal, 11(12s): 9-13.

Anjum, S.A., Ashraf, U., Tanveer, M., Khan, I., Hussain, S., Shahzad, B., Zohaib, A., Abbas, F., Saleem, M.F., Ali I., and Wang, L.C. (2017). Drought induced changes in growth, osmolyte accumulation and antioxidant metabolism of three maize hybrids. Frontiers in Plant Science, 8:1-12.

Anonymous. (2013). Ministry of Food and Agriculture, Bureau of Statistics. Government of Pakistan

Aslam, M., Zeeshan, M., Maqbool M.A., and Farid. B. (2014). Assessment of drought tolerance in maize (Zea mays L.) genotypes at early growth stages by using principle component and

biplot analysis. International Journal of Science and Technology, 29:1943-1951

Çakir R. (2004). Effect of water stress at different development stages on vegetative and reproductive growth of corn. Field Crops Research, 89: 1-16

Chohan, M.S.M. (2012).Genetic basis of drought tolerance and other plant traits in (Zea mays L.). PhD Thesis, Deptt. Plant Breed. Genet., Univ. Agri. Faisalabad, Pakistan.

Falconer. D.S., and Mackay, T.F.C. (1996). Introduction to quantitative genetics. 4th ed. Pearson edu. Ltd. England

FAO (2013). Food and Agricultural Organization of the United Nations (FAO), FAO Statistical Database, http://faostat.fao.org

Farooq, M., Wahid, A., Kobayashi, N., Fujita D., and Basra. S.M.A. (2009). Plant drought stress, effects, mechanisms and management. Agronomy for Sustainable Development, 29: 185-212.

Flexas J., Gallé A., Galmés J., Ribas-Carbo M., Medrano H. (2012). The response of photosynthesis to soil water stress. In: Aroca R. (ed.): Plant Responses to Drought Stress. Berlin, Heidelberg, Springer-Verlag.

Gabriel, K.R. (1981). Biplot display of multivariate matrices for inspection of data and diagnosis. In: V. Barnett (ed.), Interpreting Multivariate Data. London: John Wiley and Sons.

Gheysari M., Sadeghi S.H., Loescher H.W., Amiri S., Zareian M.J., Majidi M.M., Asgarinia P., Payero J.O. (2017). Comparison of deficit irrigation management strategies on root, plant growth and biomass productivity of silage

[Citation: Masood, M., Ahsan, M., Sadaqat, H.A., Awan, F. (2020). Screening of maize (Zea mays L.) lines under water deficit conditions. Biol. Clin. Sci. Res. J., 2020: 7. doi: https://doi.org/10.54112/bcsrj.v2020i1.7] 
maize. Agricultural Water Management, 182: 126-138.

Hao B., Xue Q., Marek T.H., Jessup K.E., Hou X., $\mathrm{Xu}$ W., Bynum E.D., Bean B.W. (2016). Radiation-use efficiency, biomass production, and grain yield in two maize hybrids differing in drought tolerance. Journal of Agronomy and Crop Science, 202: 269-280

Johnson. H.W., Robinson H.F., and Comstock. R.E. (1955). Estimate of genetic and environmental variability in soybean. Agronomy Journal, 47: 477-83

Lawlor D.W., Uprety D.C. (1993). Effects of water stress on photosynthesis of crops and the biochemical mechanism. In: Abrol Y.P., Mohanty P., Govindjee (eds.): Photosynthesis: Photoreactions to Plant Productivity. Dordrecht, Springer.

Najeeb, S., Rather, A.G., Parray, G.A., Sheikh, F.A., and Razvi, S..M. (2009). Studies on genetic genotypic correlation and path coefficient analysis in maize under high altitude temperate ecology of Kashmir. Maize Genetics Crop News Letter. 83: 1-8

Ogunniyan, D.J. and S.A. Olakojo. (2014). Genetic variation, heritability, genetic advance and agronomic character association of yellow elite inbred lines of maize (Zea mays L.). Nigerian Journal of Genetics, 28:24-28.

Revee, E.C.R., and Robertson, F.W. (1953). Studies in quantitative inheritance. II. Analysis of a strain of Drosophilla melongastor selected for long wings. Journal of Genetics, 51: 276-316

Saseendran S.A., Ahuja L.R., Ma L., Nielsen D.C., Trout T.J., Andales A.A., Chávez J.L., Ham J. (2014). Enhancing the water stress factors for simulation of corn in RZWQM2. Agronomy Journal, 106: 81-94

Sharwood R.E., Sonawane B.V., Ghannoum O. (2014). Photosynthetic flexibility in maize exposed to salinity and shade. Journal of Experimental Botany, 65: 3715-3724.

Terashima I., Funayama S., Sonoike K. (1994): The site of photoinhibition in leaves of Cucumis sativus L. at low temperatures is photosystem I, not photosystem II. Planta, 193: 300-306.

Wang, X., Chang, J., Qin, G., Zhang, S., Cheng X., and Li. C. (2011). Analysis on yield components of elite maize variety Xundan 20 with super high yield potential. African Journal of Agricultural Research, 6(24): 5490-5495.

Yin X.G., Jabloun M., Olesen J.E., Öztürk I., Wang M., Chen F. (2016). Effects of climatic factors, drought risk and irrigation requirement on maize yield in the Northeast Farming Region of
China. Journal of Agricultural Science, 154: 1171-1189.

Zhao Z., Luo Y. (2007). Projections of climate change over Northeastern China for 21st century. Journal of Meteorology and Environment, 23: 1-4. (In Chinese)

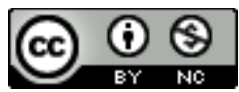

Open Access This article is licensed under a Creative Commons Attribution 4.0 International License, which permits use, sharing, adaptation, distribution and reproduction in any medium or format, as long as you give appropriate credit to the original author(s) and the source, provide a link to the Creative Commons licence, and indicate if changes were made. The images or other third party material in this article are included in the article's Creative Commons licence, unless indicated otherwise in a credit line to the material. If material is not included in the article's Creative Commons licence and your intended use is not permitted by statutory regulation or exceeds the permitted use, you will need to obtain permission directly from the copyright holder. To view a copy of this licence, visit http://creativecommons.org/licen ses/by/4.0/.

(C) The Author(s) 2021 